\title{
Barriers To Achieving E-Health Literacy
}

\author{
Laurencia Hutton-Rogers, Ph.D., Towson University, USA
}

\begin{abstract}
E-health literacy is the ability to gather and appropriately process health information retrieved online. Like traditional health literacy, higher levels of e-health literacy may work to support health decision making and thereby improve health outcomes. Some populations frequently identified as at risk for health disparities, are also in danger of falling in to the e-health literacy "gap." The following paper explores the barriers to attaining e-health literacy for vulnerable populations. The paper illustrates how a narrow focus on increasing technology access is insufficient to address disparities in e-health literacy, and provides a preliminary agenda for health promotion professionals to better address the e-health literacy gap in research and practice.
\end{abstract}

Keywords: E-Health Literacy

\section{HEALTH LITERACY AND E-HEALTH LITERACY}

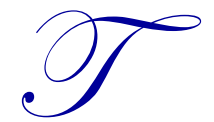

raditional health literacy focuses on the degree to which individuals can obtain and process health information to make health decisions (Norman and Skinner, 2006). Low levels of health literacy are noted to have negative impacts on health behaviors, particularly self-management of disease and patient medication compliance (Nielsen-Bohlman, Panzer, \& Kindig 2004; Parker et al., 1995; Pignone, 2005). Nutbeam (2006) describes health literacy as one of the essential goals of health education and states that health literacy can be considered an outcome measure of health education activities.

A cost effective and popular option for dissemination of health education is via the web and mobile devices. Leveraging the strengths of this new media requires a re-examining of the concept of literacy in web-based environments. E-Health literacy is defined by Norman and Skinner (2006) as, "the ability to seek, find, understand, and appraise health information from electronic sources and apply the knowledge gained to addressing or solving a health problem (p. 1)." Norman and Skinner (2006) note that e-health literacy is a composite of several core skills including traditional, health, information, media, and computer literacy.

E-health literacy continues to emerge as an important issue in health education and promotion as more Americans use web-based and mobile health resources. According to the PEW Internet and the American Life Project (Fox \& Duggan, 2013), "81\% of U.S. adults use the internet and 59\% say they have looked online for health information in the past year; thirty five percent of U.S. adults say they have gone online specifically to try to figure out what medical condition they or someone else might have" (p.1). Mobile smart phones continue to emerge as the preferred media for researching health information on the go. According to the Pew report on mobile usage, 52\% of smart phone owners gather health information on their phones, compared with $6 \%$ of non-smartphone owners (2012). Cell phone usage for health information was also common for Latinos and African Americans (Fox \& Duggan, 2012).

If the goal of E-health literacy is to improve health outcomes by making health information and health decision making tools easily accessible, issues of basic literacy, technical literacy, and linguistic and cultural barriers may further exacerbate difficulties encountered by groups already identified as suffering from health disparities. A failure to assess and implement strategies to address barriers to E-health literacy for vulnerable populations effectively serves to create more health inequalities. Examining the potential impact of E-health literacy on health behavior presents a unique challenge, because it involves a complex interplay of basic literacy skills, the ability to successfully navigate the dominant language framework (English) and culture utilized for web mediated communication, and sufficient levels of technology adoption and proficiency 


\section{LOW BASIC LITERACY}

According to a 2003 national literacy survey, approximately 30 million American adults scored at the "below basic" level in prose literacy, 27 million in document literacy, and 46 million in quantitative literacy (Kutner et al., 2007). The barriers persons with low traditional literacy encounter in their attempts to navigate our health care system, and manage their own health behaviors are significant (Berkman et al., 2011). According to a systemic review of studies on the impact of low literacy on health outcomes, low literacy levels resulted in greater hospitalizations, lower receipt of preventive screening and vaccinations, reduced medication compliance, poor interpretation of health messages and higher mortality in the elderly (Berkman, et al., 2011). Health education materials should be written at a 5 th- $6^{\text {th }}$ grade reading level (Cotugna, Vickery, \& Carpenter-Haefele, 2005). However, research reveals that patient education materials are frequently written at reading levels above $8^{\text {th }}$ grade (Cotugna et al., 2005). There's an increasing emphasis on methods to simplify health messages by simplifying language (Schwartzberg, 2005; Zaracadoolos, 2010), but there's no general agreement on the efficacy of this approach (Zarcadoolos, 2010).

While web-based environments provide an opportunity to present media rich visual and audio content, health education materials are still heavily text based. A study of 100 websites about leading incident cancers (breast, prostate, and colon) noted mean reading level grade scores from 10.7-12.9 depending on the assessment equations used in the analysis (Friedman, Hoffman-Getz, \& Arocha et al., 2006). In another study, persons with low literacy made more mistakes during web based searches, used suboptimal search strategies, exhibited greater reluctance to access additional links and high levels of difficulty interpreting the information they found online (Birru et al., 2004).

\section{LEVEL OF TECHNOLOGY ADOPTION}

There are various models of technology adoption (Straub, 2009). For the purpose of this paper, access to the technology will be referred to as base level adoption. Unequal access to technology was and continues to be an integral part of the debate over the digital divide (Ono \& Zovodny, 2006; Yu, 2006). In the US, inequality of Internet access has declined (Dimaggio \& Hargittai, 2001). However, access is still not uniform in terms of speed of access (broadband vs. low speed connections), and type of access (public vs. private, shared use vs. autonomous use) across socioeconomic tiers, and purpose of access (Dimaggio \& Hargittai, 2010; Ono \& Zavodny, 2006; Stern, Adams, \& Elesser, 2009). The elderly and persons in low socioeconomic tiers are still subject to inconsistent levels of mobile access. The US Government subsidizes low cost phone programs via their Lifeline program to help address issue of universal telecommunications access, but low cost cell phones may not be fully able to take advantage of the rich web-based environment available on smart phones, and/or they may have very limited data use plans that make web access prohibitively expensive (Hauge et al., 2008). Ball-Rokeach and Wilkins recommended that Internet connect speeds be determined before health practitioners decide to rely too heavily on the Internet to reach low income Hispanics (2009).

As web-based and mobile technology use diffuse at high rates in American society, there is an increasing awareness that access is only part of the digital inequality equation (DiMaggio \& Hargittai, 2001). Stern et al. (2009) identify three levels of digital inequality; 1) disparities in level of access to the Internet; 2) diffusion of new technologies; and 3) differences in levels of proficiency in web usage. For the purposes of the current paper, the ability of persons to use available technologies effectively and proficiently will be referred to as intermediate to high levels of adoption. Intermediate to high levels of technology adoption have a direct impact on e-health literacy as the capacity to effectively search, navigate, and optimize web and mobile experiences is essential to developing e-health literacy.

Proficiency limitations are still very common for older adults (Campbell \& Nolfi, 2004; Chu, MastelSmith, \& Cesario, 2007; Xie, 2011). Campbell and Nofi (2004) proposed that exposing seniors to better e-health information about standards of care and medical practice guidelines could increase their preventive health behaviors and improve quality of treatment. According to data from the US National Health Interview Survey, older-adult users of general health services were also more likely to use health information technology (Choi, 2011). Unfortunately, older adults' use of health information technology is still disparately low with rates ranging from 
$32.2 \%$ in the $65-74$ age range to $14.5 \%$ in the $75-84$ age range (Choi, 2011). Chu et al. (2007) attempted to address proficiency issues related to computer anxiety, computer self-confidence, and computer self-efficacy in seniors in hopes of improving their health information retrieval capabilities.

\section{ENGLISH LANGUAGE AND CULTURAL FRAMEWORKS FOR WEB MEDIATED COMMUNICATION}

The social constructivist perspective on information inequality proposes that being aware of cultural differences is essential to bridging the gap between the information rich and poor ( $\mathrm{Yu}, 2006)$. This perspective may be very applicable to the web where over $90 \%$ of online content is in English (OECD, 2001) and developed from English speakers' cultural perspectives.

The English as a primary language paradigm clearly dominates the web, and the ramifications for English as second language speakers is quite important when looking at disparities in e-health literacy. In their study of food and health institutional websites, Singh et al. (2007) estimated that $80-90 \%$ of health institutions did not translate their information into multiple languages. In 2005, only 34\% percent of state health department web sites provided information in non- English formats (West \& Miller, 2006). West and Miller (2006) noted that if federal education policy standards requiring access to services for non-English speakers were applied to state health department government web sites, most states would not meet the bar.

Ethnicity as a single factor may have less impact than language on e-health literacy. In their study of internet based pediatric development screenings among low income families, Hambridge, Phibbs, and Bergman (2001) found English as a primary language, and maternal education were the dominant factors in program participation, not ethnicity. The English as a second language barrier may also explain in part why some Hispanics categorized linguistically as "Spanish dominate" still expressed a greater preference for low technology health education modalities such as videos and taped phone messages (Gordon \& Iribarren, 2008). Singh et al. (2007) noted that among non-English speakers, there's a strong desire to use health search terms in the indigenous language. This is potentially very problematic if search engines and sites do not recognize those terms.

While there are tools like "Google translate" available to translate words and phrases, language and cultural concerns do surpass vocabulary translations (Martinez, Ainsworth, \& Elder, 2008). In discussing the lack of culturally appropriate telehealth services, Tirado rightly challenges, " ... what guarantees currently exist for culturally and linguistically diverse patients to ensure that the content of mobile health communication they may receive is respectful of their language, cultural beliefs, and health literacy levels?" (p.4). Ball-Rokeach and Wilkins (2009) studied how diverse ethnic groups sought health information on and offline and one of their primary recommendations for researchers was to invest time to better understand ethnic communities unique "communication ecologies" (p.28).

\section{CONCLUSION}

Narrowing health disparities is one of the primary goals of Healthy People 2020, and increasing health literacy is a crucial step in achieving that goal (Koh et.al, 2011). Improving e-health literacy should be a comparable goal as technology continues to transform health promotion. Transferring health promotion efforts from offline to online and mobile devices does not automatically mitigate health literacy inequalities, even with improved access to technology. There's a need to further develop quantitative and qualitative assessment strategies to understand ehealth literacy barriers before relying on web-based experiences of health consumers to bridge the gaps in health promotion. There are tested algorithms to assess reading levels for health literacy like the Rapid Estimate of Adult Literacy in Medicine (REALM), and the Test of Functional Health Literacy in Adults (TOFLA), but broader consideration of other factors may be needed to assess e-health literacy (van der Vaart, 2011). Norman and Skinner (2006) devised the eHeals e-literacy scale. Measures that are available in multiple languages and validated empirically are needed (van der Vaart, 2011). Renewed basic literacy efforts as reflected in traditional health literacy concepts should continue to be a priority on a national level (Miller, West, \& Wasserman, 2007). There also needs to be a renewed commitment on the part of those producing health promotion materials to ensure the grade level of the information is appropriately scaled $\left(<8^{\text {th }}\right.$ grade reading level). Greater consideration of the role of English as a second language learners and expanded, multi-cultural frameworks for building and translating sites geared towards 
providing health information would also be beneficial. The ability to develop and provide culturally sensitive ehealth information prescriptions is essential.

Kickbush (2001) states that health literacy is "about empowerment" (p.294). Likewise, e-health literacy has the potential to positively support health consumer empowerment. However, without more careful planning for inclusive e-health environments, persons who could benefit most from additional empowerment tools will continue to be left behind.

\section{AUTHOR INFORMATION}

Niya Werts, Ph.D.; Towson University, Department of Health Science, USA. E-mail: nwerts@towson.edu (Corresponding author)

Laurencia Hutton-Rogers, Ph.D., Towson University, Department of Health Science, USA. E-mail: lhuttonrogers@towson.edu

\section{REFERENCES}

1. Ball-Rokeach, S. J., \& Wilkin, H. A. (2009). Ethnic differences in health information-seeking behavior: Methodological and applied issues. Communication Research Reports, 26(1), 22-29.

2. Berkman, N. D., Sheridan, S. L., Donahue, K. E., Halpern, D. J., \& Crotty, K. (2011). Low health literacy and health outcomes: an updated systematic review. Annals of Internal Medicine, 155(2), 97-107.

3. Birru, M. S., Monaco, V. M., Charles, L., Drew, H., Njie, V., Bierria, T., Detlefsen, E., \& Steinman, R. A. (2004). Internet usage by low-literacy adults seeking health information: an observational analysis. Journal of Medical Internet Research, 6(3).

4. Campbell, R. J., \& Nolfi, D. A. (2005). Teaching elderly adults to use the Internet to access health care information: before-after study. Journal of Medical Internet Research, 7(2).

5. Choi, N. (2011). Relationship between health service use and health information technology use among older adults: analysis of the US National Health Interview Survey. Journal of Medical Internet Research, 13(2).

6. Chu, A., Huber, J., Mastel-Smith, B., \& Cesario, S. (2009). "Partnering with Seniors for Better Health": computer use and internet health information retrieval among older adults in a low socioeconomic community. Journal of the Medical Library Association: JMLA, 97(1), 12.

7. Cotugna, N., Vickery, C. E., \& Carpenter-Haefele, K. M. (2005). Evaluation of literacy level of patient education pages in health-related journals. Journal of Community Health, 30(3), 213-219.

8. DiMaggio, P., \& Hargittai, E. (2001). From the 'digital divide'to 'digital inequality': Studying Internet use as penetration increases. Princeton: Center for Arts and Cultural Policy Studies, Woodrow Wilson School, Princeton University, 4(1), 4-2.

9. Fox, S., \& Duggan, M. (2012). Mobile Health 2012.Pew Internet and the American Life Project, November 8, 2012. http://pewinternet.org/Reports/2012/Mobile-Health.aspx

10. Fox, S., \& Duggan, M. (2013). Health Online: 2013. Pew Internet and the American Life Project, January 15, 2013. http://pewinternet.org/Reports/2013/Health-online.aspx

11. Friedman, D. B., Hoffman-Goetz, L., \& Arocha, J. F. (2006). Health literacy and the World Wide Web: comparing the readability of leading incident cancers on the Internet. Informatics for Health and Social Care, 31(1), 67-87.

12. Gordon, N. P., \& Iribarren, C. (2008). Health-related characteristics and preferred methods of receiving health education according to dominant language among Latinos aged 25 to 64 in a large Northern California health plan. BMC Public Health, 8(1), 305.

13. Hambidge, S. J., Phibbs, S., Beck, A., \& Bergman, D. A. (2011). Internet-based developmental screening: a digital divide between English-and Spanish-speaking parents. Pediatrics, 128(4), e939-e946.

14. Hauge, J. A., Jamison, M. A., \& Todd Jewell, R. (2008). Discounting telephone service: An examination of participation in the Lifeline Assistance Program using panel data. Information Economics and Policy, 20(2), 135-149. 
15. Kickbusch, I. S. (2001). Health literacy: addressing the health and education divide. Health Promotion International, 16(3), 289-297.

16. Koh, H. K., Piotrowski, J. J., Kumanyika, S., \& Fielding, J. E. (2011). Healthy People A 2020 Vision for the Social Determinants Approach. Health Education \& Behavior, 38(6), 551-557.

17. Kutner, M., Greenberg, E., Jin, Y., Boyle, B., Hsu, Y. C., \& Dunleavy, E. (2007). Literacy in Everyday Life: Results from the 2003 National Assessment of Adult Literacy. NCES 2007-490. National Center for Education Statistics.

18. Nielsen-Bohlman, L., Panzer, A. M., \& Kindig, D. (2004). Health Literacy: A Prescription to End Confusion. Committee on Health Literacy, Board on Neuroscience and Behavioral Health, Institute of Medicine of the National Academies.

19. Martinez, S. M., Ainsworth, B. E., \& Elder, J. P. (2008). A review of physical activity measures used among US Latinos: guidelines for developing culturally appropriate measures. Annals of Behavioral Medicine, 36(2), 195-207.

20. Norman, C. D., \& Skinner, H. A. (2006). eHealth literacy: essential skills for consumer health in a networked world. Journal of Medical Internet Research, 8(2).

21. Organization for Economic Co-operation and Development (OECD), 2001. Understanding the Digital Divide. OECD, Paris.

22. Ono, H., \& Zavodny, M. (2007). Digital inequality: A five country comparison using microdata. Social Science Research, 36(3), 1135-1155.

23. Parker, R. M., Baker, D. W., \& Williams, M. V. (1995). The test of functional health literacy in adults. Journal of General Internal Medicine, 10(10), 537-541.

24. Pignone, M., DeWalt, D. A., Sheridan, S., Berkman, N., \& Lohr, K. N. (2005). Interventions to improve health outcomes for patients with low literacy. Journal of General Internal Medicine, 20(2), 185-192.

25. Schwartzberg, J. G., Jonathan. VanGeest, \& Claire. Wang. (2005). Understanding health literacy. Chicago, IL: AMA press.

26. Tirado, M. (2011). Role of mobile health in the care of culturally and linguistically diverse US populations. Perspectives in Health Information Management/AHIMA, American Health Information Management Association, 8 (Winter).

27. van der Vaart, R., van Deursen, A. J., Drossaert, C. H., Taal, E., van Dijk, J. A., \& van de Laar, M. A. (2011). Does the eHealth Literacy Scale (eHEALS) measure what it intends to measure? Validation of a Dutch version of the eHEALS in two adult populations. Journal of Medical Internet Research, 13(4).

28. West, D. M., \& Miller, E. A. (2006). The digital divide in public e-health: barriers to accessibility and privacy in state health department websites. Journal of Health Care for the Poor and Underserved, 17(3), 652-667.

29. Xie, B. (2011). Older adults, e-health literacy, and collaborative learning: An experimental study. Journal of the American Society for Information Science and Technology, 62(5), 933-946.

30. Yu, L. (2006). Understanding information inequality: Making sense of the literature of the information and digital divides. Journal of Librarianship and Information Science, 38(4), 229-252.

31. Zarcadoolas, C. (2011). The simplicity complex: exploring simplified health messages in a complex world. Health Promotion International, 26(3), 338-350. 
NOTES 